\title{
Implementation of Outsourcing Strategy: An Empirical Investigation of Selected Sugar Processing Companies in Kenya
}

\author{
Charles K. Muteithia \\ Agri-Food Development Program \\ Embassy of Ireland-Nairobi \\ Kenya \\ Vincent N. Machuki, PhD \\ School of Business \\ University of Nairobi \\ Kenya
}

\begin{abstract}
Organizations seeking to gain and sustain competitive advantage choose, among other strategies, outsourcing strategy. However, companies are bound to encounter different challenges during the implementation process. Kenya's sugar processing companies confront a number of challenges and outsourcing of noncore activities has emerged as one of the many strategies they adopt to mitigate these challenges. The study intended to establish the outsourcing strategy implementation practices, the challenges of implementing outsourcing strategy, and the measures to deal with the challenges. Through a multiple-case study design, both primary and secondary data were collected from senior managers and relevant documents respectively; and analyzed using content analysis. The findings indicate that the companies outsourced non-core activities to external firms motivated by focus on core competencies, access to specialized skills, and cost reduction. Ineffective management of the implementation process, resistance to change from the workforce, and conflict of interest from employees were common implementation challenges faced by the companies. To mitigate these challenges, top management were found to be involved in the outsourcing steps, staff members are provided and availed sufficient information about change, there were open communication channels within the organizations as well as adequate policies and operating procedures that guide members of staff while undertaking various activities. The study concludes that outsourcing is beneficial to the companies, the companies have documented the process, service providers have duly signed contracts, and the differences in the activities outsourced are attributed to the number of years the companies have been in operation, ownership structure, and oversight system. The study provides support for Agency and Transaction Cost Economics theories with regard to the implementation of outsourcing and partially concurs with extant empirical literature. The study recommends that companies should step up enforcement of the current applicable rules, regulations and policies; dispute resolution mechanisms should be strengthened; the companies should renew their focus on staff training at all levels; and regular benchmarking should be undertaken with the best in class to learn as well as share experiences. Based on the limitations of the study areas for further research have been suggested.
\end{abstract}

Keywords: Implementation, Outsourcing Strategy, Sugar Companies

\section{Introduction}

The competitiveness of a country is attached to the ability of its industries to continuously invent and make better products (Porter, 1994). The dynamism of this competition within an industry and its manifestations varies over time. A company will therefore attain an upper hand over competitors by coming up with a new approach of doing things, deploying new technology, and continuous innovation. It is for this reason that managers are now focused on employing strategies that will propel their organizations to have an edge over competitors. To this end, outsourcing has emerged as a vital and integral part of successful business operations in cost savings and improving efficiency. Isinga and Werle (2000) acknowledged the attractiveness of outsourcing at strategic management level, but cautioned against difficulties experienced during the implementation stage. This is because the strategic intent tends to be lost while dealing with the problems encountered in every day operational activities. 
Outsourcing strategy is one of the most common and widely adopted business strategies worldwide resulting from increased competition among businesses and the need to access resources in the market. The process involved is complicated and with diverse activities that Perunovic and Pedersen (2007) grouped into; preparation, vendor selection, transition, relationship management, and reconsideration stage originating from seven different processes advanced by Greaver, 1999; Momme, 2002; Cullen and Willcocks, 2003; Corbett, 2004; Click and Duening, 2005; and McIvor, 2005. These scholars are yet to coalesce to a single agreeable and acceptable process to implement outsourcing.

In Kenya, agriculture is by far the most prominent, important and dominant industry and the mainstay of the economy (Deloitte, 2016). According to data released by the Kenya National Bureau of Statistics (2017) the agricultural sector supports livelihoods of at least $25 \%$ of the Kenyan population while directly contributing $25.9 \%$ to the GDP with the sugar sub sector being a major contributor. The sugar industry is however characterized by rising input costs, low productivity, and influx of cheaper imports from low cost producers among other challenges. To this effect, outsourcing of non-core activities has emerged as one of the many strategies being implemented by the sugar factories to mitigate these challenges. The intensity of the practice is rampant in many sugar companies where cane harvesting, legal, security, maintenance, repairs, cane transport, and marketing services being some of the outsourced services (Manyasi \& Omusotsi, 2014; Owuor, 2016).

Sugar companies in Kenya have been grappling with multiple challenges arising from high production costs, low production capacity, reliance on rain fed agriculture, huge debts, managerial inefficiencies, cane poaching and outdated technology that have reduced competitiveness and attractiveness of the industry to new investments. These challenges have made the country a high costs sugar producer and exposed the industry to threats from cheap imports from more efficient sugar producing countries necessitating the need for coordinated strategic response. Jowi (2010) identified outsourcing as one of the strategies being implemented as a response to the environmental challenges. However, the success or otherwise of this strategy ultimately depends on how the company undertakes the implementation process.

Sugar is a widely traded basic commodity in the world. However, the benefits that come with this trade have remained elusive to the country and the numerous local companies in the industry. The bases for establishing sugar factories by the government were to achieve self sufficiency in production and exporting surplus quantity. However, self sufficiency has eluded the sector as consumption continues to outstrip production, the deficit being imported from COMESA and other low cost sugar producing countries. This calls for the industry to transform itself to profitability by reducing costs and enhancing efficiency through sound management practices that will ensure survival in the increasing competitive and changing environment.

The initial objectives of the Sugar Industry were more social than economic in orientation, but with the changing global trends, the latter is being given more prominence. The Sugar Act (2001) prescribes that factories should concentrate on milling and selling of quality sugar, and to be able to do this effectively and efficiently, sugar companies have resulted in outsourcing non core activities (Owuor, 2016). The annual domestic requirement of sugar currently is 800,000 MT while the production capacity stands at 600,000 MT making the country a net importer (Economic Survey, 2017). The Government owns five companies that have been earmarked for privatization to inject the much needed capital boost to rehabilitate and modernize them. This has resulted into the country seeking extension of the COMESA sugar safeguards to 2019 to enable privatization of state owned millers faced with a myriad of challenges.

In Kenya sugar is produced in Nyando, Western Kenya, South Nyanza and Coastal sugar belts. There are thirteen sugar factories that can be broadly classified into three ownership structures of Listed Company, Private Sector Companies, and Parastatals. Mumias Sugar Company is the only listed company in the Nairobi Stock Exchange. Private companies include; West Kenya, Butali, Kibos, Sukari, Transmara, Soin, and Kwale Sugar. Public sector companies include; South Nyanza, Nzoia sugar, Chemelil, while Muhoroni, and Miwani are in receivership. In the recent past, the number of private mills has been increasing and so is their sugar production against the dwindling fortunes of state owned millers.

The sugar companies selected for the study were Mumias Sugar Company Ltd (MSC), West Kenya Sugar Company, and South Nyanza Sugar Company Limited (Sony Sugar). The three sugar companies are representative of the dominant ownership structure in the industry and they have different systems of oversight, decision making process, management, and governance structures. 
Mumias Sugar Company Ltd (MSC) was incorporated in 1971 and is the largest sugar producer. It is an integrated factory with installed capacity of 270,000 MT sugar plant, $38 \mathrm{MW}$ Co-generation Plant, and 22 Million litre Ethanol Distillery. MSC is the only listed company on the Nairobi Stock Exchange after being privatized in late 2001. It has over 145,000 shareholders with the government being the largest single shareholder holding a $20 \%$ stake. MSC oversight responsibility is placed with the Board in compliance with statutory and regulatory requirements that includes; Companies Act 2015, Capital Markets Act, and Crops Act, 2013. The Company has adopted various strategies to ensure that it remains competitive in the market like offering differentiated products. As the market leader, MSC has diversified into power generation and ethanol distillation to overcome threats posed by its competitive environment (Mumias Sugar Company).

Sony Sugar was established in 1976 under an Act of parliament with the following objectives; increase national sugar production to reduce import dependency, jobs creation to local communities and to enhance the region development. The Government of Kenya own majority shares at 98.8\%, Industrial and Commercial Development Corporation (ICDC) $0.71 \%$, Industrial Development Bank (IDB) $0.28 \%$ and Mehta Group International (MGI) $0.21 \%$ as minority shareholders (Sony Sugar Company). From the shareholding, Sony Sugar can be classified as a state corporation (Parastatal) by virtue of the Government holding majority shareholding in the company. It has a crushing capacity of 3,000 TCD, where the Board of directors appointed by the President is responsible for the business performance in compliance with statutory requirements that include; State Corporations Act, 2015, Public Procurement and Asset Disposal Act, 2015, and Agriculture Fisheries and Food Authority Act, 2013.

West Kenya Sugar Company is a privately owned sugar company which was established in 1981 with an initial crushing capacity of 500 TCD to its current crushing capacity of 5,000 TCD making it the second largest Miller in Kenya. Unlike the other sugar factories that were established earlier, the company lacks a nucleus estate to grow its own cane, has no formal contracts with farmers and it is surrounded by a number of jaggeries that form part of its operational challenges. The industry's rapidly changing external environment as well as diverse ownership structure of factories within the industry makes it a case worthy of study on the implementation of outsourcing strategy.

Once a company has settled on a given strategy, implementation is the next step that translates it into action to achieve results. It is during the implementation phase that companies encounter many unpredictable challenges that complicate the process, with different organizations experiencing different challenges. Studies carried out in Western Europe and North America on how companies implement outsourcing strategy have concluded that most of them approach outsourcing improperly lowering their competitiveness that favors cost-efficient and inventive firms in other regions (Quinn \& Hilmer, 1994). Locally, Gichohi (2010) identified lack of an effective framework for implementation as a challenge, while top management involvement and lack of employees' commitment affected implementation as stated by Ochieng (2009). Studies have also been conducted in different industries on the implementation of outsourcing strategy. Sesi (2014) looked at the challenges of implementing outsourcing strategy by Commercial Banks in Kenya, while Kipkurui (2015) studied the implementation of business process outsourcing by government agencies under the ministry of information and communications technology among other scholars.

Whereas a number of studies have been undertaken on the implementation of outsourcing strategy in Kenya, their challenges, findings, and recommendations may not be applicable to the Sugar Industry. This is because they were done in a different context and time therefore creating a gap in knowledge. It is also evident that scholars and practitioner communities are yet to agree on a single outsourcing implementation process. Therefore, when different companies within an industry make a choice to outsource an activity and settles on a particular implementation process that suits their uniqueness, they are bound to encounter different challenges during the implementation process. These challenges will consequently mirror the outsourcing implementation process used as well as the company management and ownership structure. This study, therefore, sought to address the knowledge gap. The major concern of the study was: How is the implementation of outsourcing strategy undertaken at the selected sugar companies in Kenya? In addressing this concern, the study specifically sought to: establish the outsourcing strategy implementation practices; determine the challenges of implementing outsourcing strategy; and establish the measures to deal with the challenges.

\section{Literature Review}

Implementation of outsourcing strategy is grounded on the Agency and Transaction Cost Economics (TCE) theories. 
Agency relationship is one of the oldest and commonest codified modes of social interaction (Ross, 1973). It emerges when two or more parties, one designated as the agent, acts on behalf of, or as a representative for the other designated as the principal in an agreed transaction. However, complications are encountered when it comes to the monitoring of the activity being undertaken by the agent and has cost ramifications to the business. Inability to have complete contracts gives rise to transaction costs that result into renegotiations between the parties as the balance of power changes (Williamson, 1979).

Agency theory justifies the formation of alliances between companies and service providers (Blancero and Ellram, 1997). At the beginning, the theory focused on the relationship between managers and stakeholders (Jensen and Meckling, 1976). It was later extended to describe the relationships between different organizations. The application of this theory in outsourcing aids in interpreting the relationship between an organization and the vendor. According to Eisenhardt (1989) agency theory was originally applied to the delegation of work by the principal to the agent through contracting, and not focusing on whether they were from the same organization

Agency theory deals with two difficult situations. The first one is the agency problem, where goals of the agent do not meet the principal's, and it is difficult for the principal to verify or control the agent's behavior. The second problem entails risk-sharing. Since the two parties to the contract are risk averse, they prefer different approach to towards risk sharing. The outcome is increased agency cost for developing, monitoring and enforcing the contracts. Consequently, Gong (2003) explained that agency costs may decrease over time as principals and agents develop better relations through repeated transactions.

Transaction Cost Economics theory pioneered by Coase (1937) predicted that a firm will enlarge until the cost of organizing an extra transaction equates to the cost of carrying out similar transaction by means of exchange in an open market or the organization cost in another firm (Coase, 1937). Williamson (1979) argued that TCE is an interdisciplinary effort linking the study of economics to organization theory and overlaps broadly with the law of contract. The onset of transaction costs therefore is the inability to establish complete contracting which gives rise to renegotiations between the parties as the balance of power shifts. Majority of the outsourcing studies have employed the TCE theory (Perunovic and Pedersen, 2007; Vaxevanou and Konstaopoulos, 2015). This is because it affords outstanding tools of decision making that aid institutions at identifying activities to be outsourced, and making necessary preparations related to the resulting changes arising from within the organization.

Outsourcing is therefore based on logical considerations made by organizations that have reviewed factors associated with various transactions such as unpredictability of the environment, asset specificity, and other costs of transaction. Consequently, the lower the outcome uncertainty, higher transaction frequency, ease of evaluating tasks performed and assessing transaction interdependencies, the greater the likelihood to engage in outsourcing.

\section{The Concept of Outsourcing}

Outsourcing originates from the American phrase "outside resourcing", that can be interpreted as obtaining resources from outside the firm. It has become such an essential part of business success in today's world that one struggles to find an example where an industrial organization is not outsourcing some element or activity to a third party business (Quinn and Hilmer, 1994). Griffiths (2001) described outsourcing as the strategic application of external resources to undertake activities previously performed in house by staff using company resources. Thompson and Strickland (2007) defined outsourcing as a decision made consciously to relinquish the performance of some value chain activities within the organization and subcontracting them to external experts and allies. While Gilley and Rasheed (2008) defined outsourcing as handing over activities to a provider outside the organization's chosen core competencies.

It is evident from the definitions that outsourcing stem from the 'make versus buy' decision, and it is inspired by cost reduction, strategy and political considerations. Cost reduction and corporate strategy motivate private sector outsourcing initiatives while political considerations are predominant in public institutions (Kakabadse and Kakabadse, 2000). Isinga and Werle (2000) observed that outsourcing is inspired by the increasing pressure on the management of an organization to perform better with lean resources and against stiff competition. In the past, Griffiths (1999) noted that cost or headcount reduction have been the most common logic why companies outsourced. However, the current drivers are more strategic and focused at undertaking value addition within the organization by exploiting its own core competencies.To be able to survive and prosper, organizations must continuously respond to environmental challenges. 
In particular, they should be able to deliver against demanding and critical success factors arising from their customer needs and demands (Johnson, Scholes \& Whittington, 2008). Kakabadse and Kakabadse (2000) also noted that the objective of outsourcing is moving from cost reduction to value creation and to satisfy value creation challenges, business leaders are focusing more on outsourcing (Quelin and Duhamel, 2003). However, Porter (1994) noted that if majority of firms in an industry were to choose similar solutions like outsourcing, then the strategic advantage would not be justifiable as they would all end up with similar business models. Therefore, for outsourcing to be considered as a strategic choice, it must be a distinguishing attribute of a particular company in an industry.

\section{Implementation of Outsourcing Strategy}

The formulation of strategy requires skill to accomplish, while making it work by implementing it within the organization is even more difficult (Hrebiniak, 2006). Slater, Olson and Hult (2010) observed that strategies most often fail due to ineffective implementation. Li, Guohui and Eppler (2008) defined strategy implementation as constantly changing, repetitive and complex process, made up of a series of decisions by managers and employees affected by interrelated external and internal factors aimed at turning strategic plans into reality and to attain the strategic objectives of an organization. Aaltonen and Ikavalko (2002) observed that a superior strategy without effective implementation was useless. It can therefore be stated that implementation effectiveness is the realization of the strategic objectives through the right steps (Cespedes and Piercy, 1996).

Strategy implementation involves resource organization and staff motivation to attain set objectives (Muchira, 2013). To avoid common pit falls that results in failure, organization management should pay close attention to the implementation process. Melnyk and Christensen (2000) derived a process that managers should follow when developing and executing outsourcing: evaluate the service/product relationship to the company's core competencies; analyze the appropriateness of the product characteristics for outsourcing; assess the outsourcing reasons; evaluate the quantitative and qualitative costs, review current supplier capabilities; evaluate new suppliers; decision making and implementation; and monitor and revise the steps. The aim is to outsource works with best in class service providers with systems that can easily integrate into its operations (Brown and Wilson,2005).

The direction taken by an organization is based on the strategy set up by its top management and it is fundamental to its survival. An outstanding strategy alone cannot result in competitive advantage to an organization. This is because strategies are only statements of intent, and the implementation tasks are meant to realize the intent. Therefore, it is vital for managers to comprehend the importance of strategy implementation. Strategy implementation as described by Irwin (1995) is as an internally motivated activity involving budgeting, supervision, organizing, staff motivation, culture building, and leadership. Mintzberg (1994) pointed out that the weakness of strategic management is connected to how the implementation is undertaken. He argued that more than half of the strategies devised by organizations are never implemented.

Research focusing on the outsourcing process has been undertaken by different scholars (Greaver, 1999; Momme, 2002; Cullen and Willcocks, 2003; Corbett, 2004; McIvor, 2005). Perunovic and Pedersen (2007) went a step further and grouped the various stages identified in the outsourcing process into: preparation stage, vendor(s) selection, transition stage, relationship management, and finally reconsideration stage. Each of these stages provides answers to various questions during the implementation of the outsourcing process. The preparation stage answers the questions what, where, when and how? Vendor(s) selection answers the question whom to? Transition and Relationship management stages answers the question how? While the Reconsideration stage, answers the question what now? This emphasizes the complicated nature of the outsourcing process necessitating careful management throughout the cycle.

Outsourcing has evolved as one of the most common and widely adopted business strategies worldwide (Willcocks, 2010). The expected benefits that attract companies to outsource include; realizing better services at lower overall cost, quality improvements, increased customer satisfaction, latest technology access, accelerated organizational learning, access to outstanding talent, ability to re-focus scarce resources onto core functions, and enabling focus on core business (Kremic, Tukel, \& Rom, 2006; Manyasi\& Omusotsi, 2014). However, some disadvantages that may include; loss of control in outsourced operations, quality control challenges, disagreements and loss of skills, data security and confidentiality loss, hidden costs, and reduced flexibility have been documented (Troaca \& Bodislav, 2012; Tuyauova, 2012). 
The choice of an organization to outsource services as a business strategy ends up modifying its legal confines, and it is for this reason that this responsibility is vested on the top management as part of corporate policy. This decision often involves several departments in large companies and alters resource allocation arrangements and asset management practices (Quélin and Duhamel, 2003). A key ingredient of a successful strategy implementation plan also involves having a clear visible leader. The whole management team i.e. the chief executive officer, heads of business units, and managers make up the strategy implementation team. The leader has the duty to clearly communicate the strategy to the key stakeholders. In addition, monitoring the progress of the strategy implementation, adapting the strategy to the changing environment, aligning organizational structure, budgets, performance and reward systems to the strategy, are additional duties of the leader.

The reasons why companies outsource services to external suppliers are many and varied and may include; risk sharing with other firms, operating cost reduction, ability to focus on core competencies, access to advanced technology, unlocking resources to competing needs, and activities that are out of control (Quinn and Hilmer, 1994; Griffiths, 1999; Kakabadse and Kakabadse, 2002). The advantages realized from outsourcing include: ability to focus on core activities, access to superior quality, cost savings, access to experience, improving performance, and flexibility. These benefits are admirable but when the process is poorly planned and executed the agreement may fail to meet its intended purpose resulting into losses. Some disadvantages of outsourcing may include; loss of control in outsourced functions, threat to data confidentiality and security, hidden costs during contracting, quality issues, teams reallocations, prospect of choosing wrong supplier, loss of critical skills and knowledge, loss of flexibility, inadequate capabilities of service provider, ineffective organizational communication, and political problems (Mullin, 1996; Tuyauova, 2012).

\section{Challenges of Implementation of Outsourcing Strategy}

Implementation of outsourcing strategy has triggered a paradigm shift in the management and strategic positioning of institutions against competition. It is a complex process that involves a variety of managerial activities i.e. planning, directing, organizing, staffing and controlling. Noble (1999) observed that even the best formulated strategies may fail to produce superior performance for the firm if they are not successfully implemented. Implementation challenges can arise from; ineffective management of the process, inadequate resource allocation, resistance to change by staff, conflict of interest among employees, poor communication, and lack of support from top leadership.

Ineffective management of the implementation process has been identified as a challenge when implementing outsourcing strategy. Beer and Eisentat (2000) observed that an ineffective top team that bypasses members of the senior team to obtain information from and gives orders to staff at lower level creates a surefire way of keeping leadership group from becoming an effective team. Fear of losing power was also identified as a reason that can make managers refuse to cooperate effectively. Ineffective management of the implementation process was also confirmed by Sesi (2014) as the greatest challenge experienced by commercial banks during outsourcing implementation process.

Inadequate resource allocation for the outsourcing implementation greatly affects the implementation process Sesi (2014). It is therefore important to budget and avail all the resources required to implement the strategy. Budgeting for activities that require financial resources motivates staff when they are able to carry out the activities successfully and avoids inadequate resource allocation. When resources are not available or availed later, the staff involved gets frustrated and discouraged and do not want to participate in the implementation of outsourcing strategy. Implementation can also be hindered by inadequate financial resources, employee's competency development, talent development, job description and work allocation (Wilson \& Brown, 2005).

Resistance to change can be detrimental to the implementation of outsourcing in any organization (Ombasa, 2013). There is need to handle staff issues competently because staff members generally have a negative perception on outsourcing as an underestimation of their skills (Barthélemy, 2003). At Kenya Post Office Savings Bank employees resisted change and wanted to maintain their organization culture. This could have been as a result of fear of the unknown from the employees whose services were to be outsourced.

Conflict of interest among employees (senior management) and suppliers is a considerable challenge to the implementation of the outsourcing strategy (Kiptoo, 2012). Managers at lower to intermediate-level also tend to be actively hostile to outsourcing fearing loss of jobs, prestige, or power. 
Kamuri (2010) found out that most people working in the department of procurement and supplies would prefer the status quo to remain in order to protect their self interests. It is therefore important to ensure that the supervision of outsourced operations is not assigned to someone who has a vested interest in the way things were done before. This is because they can easily become detractors and not champions, sabotaging the relationship.

Poor vertical communication has been identified to inhibit effective implementation of business strategy. Peng and Littlejohn (2001) identified effective communication as a key requirement for effective strategy implementation. Communication within an organization plays a critical role in training, knowledge dissemination and learning while implementing business strategy. Communication barriers are reported more often than any other type of barriers such as learning, staff management, cultural or organizational structure barriers.

In addition, lack of support from the organization top leadership may adversely affect outsourcing strategy implementation process. Top management support from the beginning all the way to implementation is very important otherwise it might not succeed (Ombasa, 2013). Top management refers to senior-level leadership, owners, and other senior executives (Quinn, 1999). As a strategic choice, the decision to outsource must be entrusted to senior management. This also implies that for the benefits of outsourcing to be realized, it must be championed by an executive one level above those affected. It is for this reason that outsourcing recommendations in many organizations are unlikely to come from below but mostly they are initiated by top management.

\section{Measures to Mitigate the Challenges}

As pointed out in the earlier section, challenges and reasons abound for the failure of outsourcing arrangements. The reasons are distinct to a particular organization, the process followed and the prevailing situations. It is important to note that failed outsourcing endeavors are seldom made public as the information is considered damaging to a firm reputation. However, worthwhile "best practices" can be obtained from the failure more so when compared to successful outsourcing efforts (Barthelemy, 2003). To ensure successful implementation, organizations have employed the following measures.

To overcome the challenge posed by ineffective management of the implementation process, DeLisi (2001) recommended that organizations should involve the top team as a group in all steps in the change process so that its effectiveness is tested and developed. He also noted that behavioral change does not follow a straight path and it requires active participation from all parties to bring out and iron out unproductive behavior, followed by reflections and learning from each other. Organization leadership must therefore oversee a learning process by being involved and actively benefitting from the lessons.

The outsourcing strategy might fail due to inadequate resource being allocated to the process. A supporting budget should be set aside for the implementation process because at the start the cost might be very high but later the benefits will be realized (Ombasa, 2013). Higgins (2005) asserts that it is the responsibility of management to avail adequate resources required to execute the formulated strategy. Resources consist of monetary, human, technological and managerial systems People are the key strategic resource to an organization (Lorange, 1998). It is therefore important that an organization should deploy personnel with the right skill set to implement the outsourcing strategy.

Resistance to change is inevitable, and management must be prepared to respond to it (Fine, 1986). Employees resist change primarily due to the fear of the unknown. Organizations should counter the resistance through corrective management action. Baker (1987) identified the following corrective actions; availing sufficient information about change, being empathetic to staff fears about change, committing sufficient resources to ease the transition process, reducing employee frustration, and working constantly at creating an environment that encourages employees to explore and test new ideas.

Political pressure has major influence on public sector organizations since the decision making process is influenced by factors that are beyond cost and profit. It is therefore important to ensure that proper corporate governance and ethics have been established to counter these political forces, and to develop clear criterion to be followed while selecting vendors to provide services that have been outsourced (Kiptoo, 2012). In addition, adequate policies and operating procedures should be put in place to aid in the implementation of the outsourcing strategy as most staff members will shun violating set policy or disregarding rules. This calls for innovation when coming up with policies that can support compelling strategy implementation. 
Communication is critical to an organization that aims at attaining success in strategy implementation. Peng and Litteljohn (2001) highlighted the important role played by effective communication towards the realization of an effective strategy execution in an organization. It is therefore the duty of management to clearly communicate to staff members and avail information about the new strategy while alleviating any fears and providing explanations on new tasks to those affected. The communication should flow from bottom to top to enable close monitoring of the implementation process and the subsequent evaluation by management on the need to make changes to the process (Beer and Nohria, 2000).

It is very important for the strategy formulators to show genuine personal commitment to its implementation as this directly affect motivational level among the implementing managers and employees (David, 2007). An organization management must be able to translate the strategic vision into concrete steps that gets things done. This supportive leadership from top management is critical in surmounting the implementation challenges.

\section{Methodology}

A multiple-case approach was adopted to provide an in-depth understanding of the implementation of outsourcing strategy, and a robust and thorough ground for quality research. Yin (2003) described multiple-case design as the process of conducting several case studies or experiments. The design strengthened the findings through comparing and contrasting the findings derived from each of the cases. This in turn encouraged the consideration of what was unique, what was common across cases and promoted theoretical reflection on the findings (Bryman $\&$ Bell, 2015). The evidence obtained from multiple-case research is considered more powerful and compelling making this approach a very useful tool to obtain deep understanding of how organizations come to grips with complex strategic decision making (Ulaga \& Sharma, 2001).

The researchers gathered data from the three companies by use of an interview guide and a secondary data capture form. Primary data was collected through a self administered interview guide developed along the study objectives guided by a review of literature. The interviewees were senior managers in the organizations involved in the implementation of outsourcing strategy.

Secondary data related to the practices as documented in the different organization documents that included strategic plans; project initiation documents; request for proposals; prequalification of suppliers' advertisements; outsourcing contracts; service level agreements; meetings schedules.

Data analysis involved processing of the collected data in a manner conforming to the laid out purpose outlined while developing the research plan. Data collected in this study was qualitative and was analyzed using content analysis. Cooper and Schindler (2003) described content analysis as objective, systematic, and qualitative description of the manifest and latent content of a communication.

After conducting interviews with the various senior managers and secondary data capture from the relevant documents, the data were collated, edited for completeness, and organized along key themes and sub themes of the study and then presented in prose form. Analysis involved comparisons and contrasting. Secondary data obtained from the various documents complemented primary data and the findings presented along the study themes.

\section{Findings and Discussion}

This section presents the research findings of the study along the study objectives and across the three sugar companies selected for the study: Mumias Sugar Company, West Kenya Sugar Company, and South Nyanza Sugar Company. The findings for each case are analyzed independently followed by cross cutting and comparative analysis of the cases and a discussion of the findings within the context of theory and empirical literature.

\section{Implementation of Outsourcing Strategy}

The study sought to establish how the three companies implement outsourcing as a corporate strategy. In order to accomplish this objective, the research studied the practices within the companies to undertake the outsourcing process.

\section{Mumias Sugar Company}

The findings of the study indicate that production and sale of sugar, ethanol, electricity, and water is the core business of the company. 
Towards this end, the company has outsourced the following activities: land preparation, fertilizer distribution, mill and seed cane transportation, roads maintenance in agriculture department; machines and equipments maintenance activities, cleaning, packaging, and loading of sugar into trucks in the factory; legal services and security services in general administration, and the company guest house under human resource department. The company is motivated by cost reduction, improved business focus on the core activities, reengineering benefits of head count reduction, overcoming operational challenges in cane transportation, and access to specialized skills like welding, boilers and turbines maintenance.

The study established that weeding, land preparation, road maintenance, cleaning, and sugar loading have been outsourced to local companies within the county, while cane and sugar transportation, security, and legal services are advertised and outsourced to national companies, while boilers maintenance and specialized activities in the factory are outsourced to companies in South Africa and India that posses the expertise.

The company has spelt out in its five year strategic plan 2013-2017 the optimization of benefits from outsourced activities as a strategy to optimize factory operational costs. It is from the plan put together by management and the board of directors that departments draw their decision to outsource an activity. Company employees are involved in the implementation of the plan where activities are cascaded to all staff which also forms part of their performance appraisal. The board of directors provides guidance to top managers and is answerable to the shareholders. The plan provides for continuous review to ensure it remains valuable given the dynamism of the environment

The company procurement policy manual details the process to be followed when procuring services from external suppliers, the procurement rules, procedures and relevant documentation required during the undertaking. The study found out that an interdepartmental team is appointed and mandated to undertake an outsourcing activity as a project. A review of the tender advertisement made in National newspapers and the company website for Seed cane and Fertilizer Distribution to Mumias Nucleus and Out growers Plantations contains the general conditions, service requirements, tender security, evaluation criteria, contractual duration of one year, evaluation criteria, contract signing and standard forms to be filled. These requirements are also applicable to the other outsourced services. In undertaking the work outsourced, the contractors are directly supervised to ensure that the work allocated is done to completion while scheduled weekly and monthly meetings are used to review progress, communicate and resolve disputes that arise.

The study also sought to establish whether outsourcing has been beneficial to the company. The research identified a number of benefits realized by the company like improvement of the business focus on core competences by outsourcing non core activities to external companies that have built competence undertaking the services like cane transportation. This also converted fixed cost into variable cost and freed resources from non core activities to other key areas while decreasing staff numbers and costs. The company has been able to access highly specialized skills required during the annual factory maintenance, and achievement of better control of workforce and wages.

\section{West Kenya Sugar Company Limited}

The study found out that sugar production is the core business of the company. The company has also categorized various activities into core and noncore. Core activities are sugar processing and cane transportation which have a direct relation to the company existence and continued operation, while noncore activities include: land preparation services to farmers, cane weeding, security and cleaning services within the company in administration, sugar bagging, loading, and transportation in factory department.

It was also established that the motive to outsource non core activities include; better focus on core business, cost reduction, and access to specialized skills. The company has outsourced non-core activities that do not require specialized skill like cleaning, security, and cane transportation services to local contractors, sugar transportation to national contractors as a return load arrangement, and the skilled maintenance activities in the factory to international firms.

Outsourcing is guided by the procurement policy which has documented the process to be followed, parties involved, and the roles and responsibilities of each party. The manager pointed out, "Cost saving is a critical consideration during the justification process in this company; cost elements are reviewed at various stages by different teams to ensure the company obtains the best deal in the market", (Procurement Manager) 
The first step in the process is the identification of the activity to be outsourced and coming up with the justification. This is followed by tendering which describes the activity, conditions of tender, evaluation criteria, submission content and format, and conditions of contract. Interested companies respond indicating their suitability and advantage over competition, which is followed by tender evaluation in accordance with the tendering criteria and value for money. The best company is invited for interviews and final negotiations on cost are held before a contract is awarded.

The findings of the study indicate that all vendors have one year duly signed contracts which include among others; rights and responsibilities, expectations, manpower, supervisory, safety, and insurance. The two parties come up with a SLA indicating performance targets, and reporting. The study also found out that contractor supervision is done by staff of the areas where they work and scheduled weekly meetings are used to review the work performed, targets attainment, safety checks and compliance, addressing accidents and incidents as well as identify and resolving emerging issues.

Communication of outsourced activity is done by the CEO to members of staff the staff and contract renewal is based on the contractor performance evaluation. Finally it was established that better focus on the company core business, better workforce control, and reduced workforce cost are some of the benefits that have been derived from outsourcing.

\section{South Nyanza Sugar Company}

The core business of the company as pointed out by the respondent and clearly captured on the company strategic plan for the year 2014-2019 is sugar production. The production process has various activities with the key activities being undertaken by the company and the noncore activities are outsourced to external firms. The findings of the study indicate that noncore activities include; weeding, and harvesting in agriculture; waste management, sanitation and ground maintenance in quality department; security services, canteen services under general management; and various maintenance services in the factory department. The motive behind the outsourcing is cost reduction, focus on core activities, access to specialized capabilities especially in the factory, improvement of operational efficiency and risk sharing in security services.

The company has outsourced weeding, waste management, harvesting and sanitation services to companies within the county, while security and some factory maintenance have been outsourced nationally and internationally depending on skill requirements. Identification and screening of potential vendors is done in accordance with the Public Procurement and Disposal Act (2005) and the company procurement policy which prescribe the procurement process from planning, to contracting. It also details the various methods of procurement of services within the state corporations in Kenya. The Act prescribes the duration for various contracts depending on contract framework and performance ranging from one financial year to a maximum three years. A review of security, waste management, sanitation and grounds maintenance contracts established that they run through the financial year.

The respondent noted that the relationship with vendors is based on partnership for consistency and continuity which enables continuous supervision and monitoring of the work being done and resolution of any disputes that might have occurred. There are scheduled weekly meetings with the contractors that review the work done in the Environment Health and Safety Section that oversee outsourced sanitation, landscaping and waste management services. The company strategic plan developed by the management team and the board of directors has set the company strategic direction and outlined implementation plans, monitoring and evaluation, and financial requirements. The study found out that the plan is communicated to staff by the corporate strategy manager and the respective line managers and guides business units while identifying activities to be outsourced.

Finally it was established that outsourcing has resulted into numerous benefits to the company that include: greater focus on sugar manufacturing, access to specialized skills in the factory like boilers and mill maintenance, decreased staff levels that had been employed in security, grounds maintenance and cleaning services that now have been outsourced, cost savings as presented in the board paper to justify outsourcing of grounds maintenance, improved efficiency and quality of work and general cleanliness of the work place and in the estates.

\section{Challenges of Implementing Outsourcing Strategy}

The second objective of the study was to determine the challenges being experienced while implementing outsourcing strategy. The respondents were asked to highlight and discuss these challenges and whether the company faced some of the documented challenges common while implementing the outsourcing strategy. 
This section addresses the second objective of the study and details interviewee response.

\section{Mumias Sugar Company}

The findings of the study indicate that MSC has experienced implementation challenges. The respondent pointed out the following challenges; industrial unrest within the contractor companies that have affected the operation of sugar miller in the past case in point being the tractor drivers working for the cane transporters an activity that has been fully outsourced by the company. This affects factory operations due to lack of cane as well as other stakeholders like farmers and cane harvesters. The respondent also pointed out that the contractors have engaged unskilled staff in the past to cut on cost against the contractual terms or deploying fewer members or equipments to undertake various activities case in point being in the sugar loading where contractors sometimes deploy fewer loaders slowing down tractors turnaround time, fewer security personnel being deployed in various areas, cane transporters availing fewer equipment and support staff to undertake the work allocated to them.

The study also found out that lack of commitment by staff members to the implementation process, open hostility towards the contractors engaged to provide cane transportation services and laxity in the supervision of the contractors was a big problem initially when the company made the decision to outsource cane transportation which was one of the big section within the company. Outsourcing resulted in the retrenchment of many employees working in the transport section and supporting sections like fleet management. The company has also experienced challenges while supervising work undertaken by contractors especially in cane transportation and those contractors undertaking highly specialized work in boiler maintenance in the factory resulting in higher monitoring cost.

It was also established that the contractors have become more reliant to the company to provide services that they are supposed to provide to their employees like emergency medical response at the company medical facility, providing fuel advance to land preparation and fertilizer distributors and constantly being forced to intervene in various industrial matters like delayed staff payment and other staff welfare cases that cause disruptions to the company operations when not fully addressed by the contractors in goodtime.

The study found out that resistance to change was experienced in the initial decisions to outsource some activities especially from the union leaders. The manager said, "The leadership of employee union will always defend their members by opposing any idea or move that comes from management that aims at retrenching or reducing the number of their members". (Manager Revenue Accounting)

The findings on conflict of interest indicate that there have been cases of conflict of interest especially where employees are also sugarcane farmers, have contracts to provide fertilizer transportation services, have relatives or business associates as suppliers of goods and services to the company. This is being experienced from all cadres of employees.

Finally it was established that the company has avoided the challenge of allocating inadequate resources to outsourced activities by ensuring that managers are responsible for initiating budgets for their business units. The manager stated that to avoid failure, outsourced strategic activities are given first priority when the company is budgeting and allocating funds. Budget utilization is also an important financial objective that is reviewed during performance appraisals. The company has also avoided resistance to strategic outsourcing and lack of top management involvement by engaging the company management and stakeholders while crafting the strategic plan that articulates the company strategic intent. The findings indicate that communication is done at the business unit level and at corporate level by the human resource department thus avoiding the challenge of ineffective communication.

\section{West Kenya Sugar Company Limited}

The study found out that the company has outsourced non core activities that do not require specialized skills and competencies to a large extent. This has had an effect of reducing the challenges encountered during the implementation process. Ineffective management of the implementation process was experienced at the initial stages of outsourcing current services since the company had not developed adequate internal capacity to define contractual terms, develop better monitoring tools, and build supervisory skills to oversee the outsourced services.

The study also found out that once an activity to be outsourced was identified, justification made and approved by the MD, funds were availed through budgetary allocation to the activity to ensure that the intended objectives were met. 
It was also established that the current activities being outsourced were earmarked for outsourcing during the early stages hence avoiding resistance to change from employees. The decision to outsource any activity is thoroughly vetted and analyzed before approval to avoid resistance and conflicts. The findings of the study also indicate that the company has experienced minimal instances of conflict of interest among employees. It was also noted that contracts and payments were approved by the CEO which also acted as a deterrent to senior managers having conflicting business with the company. The involvement of top management in decision making within their departments has provided the necessary support for the outsourced activities by ensuring that financial, human, or physical resources required were made available. The manager said, "Currently the real challenge is not the lack of support, but inadequate supervision of outsourced services. Sometimes, when the contractor supervisor is not around services like cleaning are done very slowly and not the standards", (Procurement Manager)

Finally, it was established that communication within the company flows from the top downwards; the CEO communicates to the department heads who in turn communicate to their teams during meeting or through Memos. The Human Resource department also regularly communicates to staff members via written and oral communication.

\section{South Nyanza Sugar Company}

The findings of the study indicate that the company was exposed to security risk since the contracted service providers working in offices come across confidential information and documents. Similarly, security deployed across the company and staff quarters has information on company employees and various establishments. Lack of direct control to the contractors' employees that provide various services results into delayed response to issues raised as appropriate channels must be followed while communicating to the contractors. The senior manager said, "You cannot correct an activity that you come across being done in the wrong manner; you have to report the incident to the contractor supervisor of which this might be too late", (Procurement Manager)

The respondent also noted that the contractors were swift to review contract cost upwards and rarely did they review them downwards when macro environmental forces changed. The study also sought to establish the company experience with a number of outsourcing implementation challenges and the following is a summary of the response. The findings of the study found out that the company has set up a continuous supervision process and monitoring tools that include check sheets, customer satisfaction survey, and contractor inspection which ensure that all efforts are focused towards the set objectives and avoiding ineffective management of the implementation process. The study also established that before any activity is approved for outsourcing, the company mobilizes and avails necessary resources through operational and capital budgets to ensure successful implementation. However, the manager pointed out that the company has faced delays in funds disbursement and budget cuts that have adversely affected some activities in the past.

The findings of the study indicate that resistance to change from the workforce was experienced during the initial stages of outsourcing activities like landscaping, cleaning, and waste management. Political interference was also a challenge faced by the company. To quote the manager, "Contractors recruit their non skilled staff from within the factory locality and when the contractor is replaced there is resistance due to fear of job losses that has attracted the attention and interest of local and national politicians",

(Procurement Manager)

The strategic plan of the company is set by the top management which has resulted in collective commitment and support to outsourcing by initiating necessary policy guidelines and procedures followed while undertaking outsourcing. The company also sets performance targets to which managers are appraised on. The study also established that the company had experienced cases where employees with vested interest on some outsourced activities have tried to influence the award of contracts to some companies in the past. The manager said,

"Last year a vendor was disqualified and the contract award cancelled after it was found out that some employees were directors in the company and they had not made the declaration during the tendering process",

(Environmental Health and Safety Manager)

The company regularly communicates to employees at various levels using the intranet, Memos, and scheduled staff meetings which have helped to avoid ineffective and poor communication. The meetings offer an opportunity to the managers to explain and translate strategy to their teams as well as receive valuable input. 


\section{Measures to Mitigate the Challenges}

The third objective of the study was to establish measures that the companies have put in place to deal with the strategy implementation challenges.

The respondents were asked to discuss the measures that the companies were taking to overcome the impediments or stumbling blocks of outsourcing. This section outlines these measures and regulations.

\section{Mumias Sugar Company}

Strategy implementation involves processes undertaken by an organization to achieve given objectives. There are many resources required to successfully implement the outsourcing strategy. The departments develop annual work plans derived from the five year implementation of the strategic plan detailing what is to be done and the timelines. This forms the basis for budget allocation within the company and managers are appraised on how they utilize the funds allocated to these activities.

While resistance to change is inevitable, it is the role of management to handle it in a manner that does not result into more severe problems. The study established that before an activity is outsourced the company undertakes consultation with the members of staff and their union leadership to allay any fears and anxiety and to obtain support. Where layoffs are imminent, staff redeployment to other areas within the company is also considered. The study found out that senior and middle level management as well as union leadership are involved in the planning and implementation of outsourcing. In response, the manager said, "I was involved in the development of the current strategic plan together with other senior managers in the company. We actually had a retreat out of town where we were joined by members of the board to come up with the plan",

\section{(Manager, Revenue Accounting)}

Employees are also required to make annual declaration of conflict of interest by filling forms issued by the legal department.

In dealing with ineffective communication, the company recognizes that communication should explain clearly to staff members the direction the organization is going and their roles, objectives, and responsibilities. MSC process owners have the initial responsibility to communicate vertically and horizontally to their teams while setting performance objectives, during meetings and through written memos, as well as ensure that there is improved working relationship within the team. The supply chain department is also involved in communicating to vendors and contractors.

The company has embraced outsourcing as a strategic choice that provides solutions to operational challenges and focus on the core business by outsourcing non-core activities. The respondent would recommend outsourcing of non-core activities to other companies. The manager said, "Never outsource the core activities. This is because by outsourcing the core activities you will be collapsing without knowing that you are collapsing and upon realization it will be too late for the company to recover",

(Manager, Revenue Accounting)

\section{West Kenya Sugar Company Limited}

The findings of the study indicate that the company has undertaken various training programs to managers, supervisors, and contractors to bridge the gap of lack of relevant and adequate skills, which has improved the effectiveness of the implementation of outsourced activities. The trainings have focused on supervisory skills, industrial relations, and safety health and environment which are the areas where gaps have been identified. Outsourced services are also adequately funded upon approval by the CEO.

To overcome employee resistance to change, management through the relevant departments has focused on providing information to staff and seeking their input and feedback about the intended change through meetings that: explain the reasons for outsourcing and benefits to the organization, and providing a negotiation platform with the union leadership. The manager pointed, "We also give the affected employees the opportunity to form companies and become contractors to provide the services that they were initially providing while in employment", (Procurement Manager). The study established that the CEO is actively involved in determining activities to be outsourced and has become a champion to the course by closely monitoring the progress, staying informed on the implementation progress, and helping to align senior management involvement in the implementation process. It was also pointed out that the company has only outsourced a non critical activity which has reduced cases of conflicts.

138 
As noted earlier communication plays a critical role in knowledge dissemination and learning. The company has set focus on providing sufficient communication and sourcing for feedback from the process owners with outsourced services.

Regular meetings between contractors on a weekly basis and management has resulted in a harmonious working relation and improved quality of work. When asked about suggestions that can help to minimize implementation challenges, the manager said, "Before an organization sets out to outsource any activity, the justification should be well thought out and supported by well worked out economics that consider regular fluctuations in external business environment. Sourcing of vendors should be done widely and extensively and never compromise on expertise. Our negotiations with contractors are thorough during sourcing and purchasing of materials and we have made significant cost savings from it" (Procurement Manager)

Finally, when asked whether he would recommend outsourcing to other companies and in what areas. The manager said, "Core business should be viewed on a wider perspective like an area that not only incurs costs to the organization but also having a possibility of generating revenue to the company", (Procurement Manager)

This is the reason why the company has not outsourced cane transportation services since the company can manage the fleet better and at a lower cost from bulk sourcing of spares, discounts on fuel, and general savings compared to competitors or available cane transport companies that provide the service to competitors. When asked whether he would recommend outsourcing to other companies, the manager said, "I would recommend outsourcing of noncore activities that do not have potential to interrupt the main business of the company", (Procurement Manager)

\section{South Nyanza Sugar Company}

The study established that the top management in the company is actively involved in the outsourcing process from coming up with the proposal and forming justification to outsource activities; together with their team members. They are also involved in the implementation and review of the process guided by the contractual terms. The board of directors provides oversight and guidance to this team.

In dealing with inadequate resources availed for the implementation process, the process owners have the responsibility to budget for the outsourced activities and once the budget is approved the company sets aside funds for the implementation of the activity. However, it was found out that some activities have had to be abandoned or postponed due to reduction or delays in Government funding. With regards to resistance to change, the company has responded by ensuring that process owners involve their team members and union officials when coming up with proposal to outsource activities; they elaborate the benefits, and clarify any misconceptions. The company has ensured that contractors consider employees who have been laid off and people from the local community for employment as first priority.

The study found out that the company has ensured that staff members have been sensitized and trained on the requirements of ethics and anti corruption regulations, whistle blowing, and declaration of interest from staff members, public procurement and asset disposal Act, as well as providing competitive remuneration to counter conflict of interest among employees and external influence. The manager said, "The company has adequate policies and procedures that guide staff in procurement and when dealing with contractors and vendors" (Procurement Manager)

The study also established that heads of departments and the managing director are engaged in crafting the strategic plan, approving outsourcing decisions, allocating resources to outsourced services, supervision and performance evaluation of outsourced services. It was established that by involving the managers of various units the employees in those units also participate in the process. The MD is solely responsible for communicating to external sources while corporate affairs and HR departments communicate to the organization. The company encourages two way communications and provides information to staff in written or verbal form.

When asked about the steps the company was taking to minimize implementation challenges, the manager put it clearly, "We have established clear communication lines, the business unit involved also undertakes close supervision of the outsourced services, and we have an effective contract management process with a unit dedicated to deal with contracts and contractors. The company does not do away in totality with all the staff when an activity is outsourced, rather a small team is left to coordinate and manage the process", (Procurement Manager) 
Finally, it was established that outsourcing had a bright future in the company as long as current benefits of efficiency in service delivery, improved quality of work done and cost savings were forthcoming. The manager would also recommend outsourcing of noncore activities to other companies.

However, it was found out that the company was also studying and learning while implementing outsourcing and that there was need for benchmarking with other companies who have outsourced activities longer so that they can improve on their implementation.

\section{Cross-Cutting and Comparative Analysis}

In this subsection, comparison of the three cases against each other is made, listing commonalities and differences on the implementation of outsourcing strategy, challenges of implementing the strategy, and measures put in place to mitigate the challenges.

\section{Implementation of Outsourcing Strategy Discussion}

The study found out in all the three cases, activities had been segregated into core and noncore. The strategic plan of Mumias sugar 2013-2017 and Sony Sugar 2014-2019 had further identified outsourcing of non core activities as a strategy to optimize value on noncore activities. These activities are outsourced to local, national, and international companies. Noncore activities like land preparation, cleaning, bagging, loading, and landscaping services have been outsourced to local companies, while outsourcing to national and international companies is dependent on capital requirement and the level of skill required to provide the service. Mumias Sugar is the only company that has fully outsourced cane transportation services.

The motive to outsource noncore activities include: cost reduction, focus on core competencies, and access to specialized skills in the three companies. In addition, operational challenges and reengineering benefits also motivated the outsourcing of cane transportation in MSC. Concerning the process used to identify contractors, the three companies have documented procurement policies that guide the process with Sony Sugar also abiding with the Public Procurement and Disposal Act (2015), being a state corporation. All the vendors have duly signed annual contracts or covering the duration of the activity if it is less than one year.

During the study, it was established that the companies manage relationship with contractors by having meetings at various intervals monthly and quarterly where senior managers meet, and on weekly basis at operational levels to address the workings of the contract. This includes identifying and resolving any problems to ensure continued satisfaction. In all three cases, the managers noted that outsourcing was beneficial to their companies and identified the following benefits: better focus on core business, cost saving, access to specialized skills, and decreased staff levels and costs.

Finally, it was established that all the managers interviewed in the three companies were actively involved in the planning and implementation of outsourcing. In the two companies with a documented strategic plan, senior level managers and the board of directors were involved in the development and implementation of the plans by the employees while the board provided guidance and oversight. The relevant departments are engaged in a continuous evaluation of the activities and outputs as documented on the annual work plans which form the basis of performance evaluation and subsequent review. West Kenya Company did not have a documented strategic plan and the being a privately owned company; the CEO had major influence on the decision to outsource any activity as well as on the process.

\section{Challenges of Implementing Outsourcing Strategy}

In all three cases, ineffective implementation of the outsourcing process was not presented as a challenge by the managers interviewed. However, in West Kenya Sugar few cases were pointed out during the early stages of outsourcing before the company could develop the capacity to supervise and monitor contractor output. Concerning inadequate resource allocation, this was also not a challenge since the companies only outsourced activities that had been budgeted for and funds set aside towards this end.

The findings of the study indicate that the three companies have experienced resistance from the workforce towards outsourcing of various activities. This was due to the fear of job losses from employees to outsourcing companies and loss of membership from the union leadership. Top management was fully represented in the decision making process to outsource activities and provided adequate financial, human and physical resources. Conflict of interest among employees was noted in MSC and Sony Sugar by the managers as a risk that results in biased bidding process and has the impact of increasing the cost by locking out cheaper contractors. 
This was however not the case in West Kenya Sugar company. The three companies regularly communicate to their staff via verbal and written means which emanate from the MD, human resource department or the business unit leaders.

\section{Measures to Mitigate Implementation Challenges}

To overcome the challenge of ineffective management of the implementation process, West Kenya Sugar undertook the managers and supervisors working with contractors through various trainings aimed at improving the supervisory, monitoring and relations management skills. The companies have mitigated inadequacy of resource allocation to the implementation process by ensuring that all approved outsourcing activities are in the annual budget and funds have been allocated for the same. However, at Sony Sugar the risk of insufficient funding arising from government directives has impeded on procurement and resulted into stalled projects.

While resistance to change is inevitable, in the three cases it was noted that broad consultations at the business unit, departmental and corporate level are undertaken to allay fears, anxiety and to obtain support. The companies have also considered staff transfer before outsourcing activities as well as requiring the contractors to prioritize retrenched staff in their staff recruitment. Concerning lack of top management involvement, decision to outsource in the three cases are made by top managers who also have their performance contracts based on attainment of the outsourced services objectives.

It was also noted that to overcome conflict of interest in MSC and Sony Sugar, employees to declare their interest on an annual basis with the legal department, employees have also been trained on integrity and ethical behavior and have a policy on zero tolerance on corruption cases. In the three cases, the MD is the one responsible for communicating to external sources while human resource department is tasked with the role of communicating to employees supported by the departmental heads and business unit managers. The supply chain or procurement units are also involved at communicating to contractors and vendors. Finally, the documented strategic plan in

\section{Discussion of Findings}

This study was anchored on the Agency theory (Blancero and Ellram, 1997) and Transaction cost economics theory (Coase, 1937). The focus of the agency theory on two companies (outsourcer and vendor) and the relationship between the two firms has been at the centre of developing and managing outsourcing contracts. The study established that all the vendors providing services had signed contracts. Outsourcing relationship is faced with challenges which may arise when the goals of the two contracting parties are different. Difficulty in controlling and supervising the agent was manifested in the study during the outsourcing process which was mitigated by the establishment of contractor monitoring criteria, performance review, and dispute resolution mechanisms in line with agency theory. The theory is applied in the outsourcing process during contracting, relationship management and reconsideration phase.

The unit of analysis in Transaction Cost Theory is a transaction. At the beginning of an outsourcing arrangement the study found out that managers' must justify the decision to outsource by weighing the cost versus the benefits. TCE provides tools that help organizations while making the decision to outsource and while renewing the outsourcing contracts. The study found out that cost reduction was a common motive that led the companies to outsource various activities. The companies also undertook cost benefit analysis to justify the outsourcing benefits by comparing the current cost being incurred versus the cost to be charged by an external company. In the case of MSC and Sony Sugar comparative costs is an important area when preparing board papers to justify outsourcing of any activity.

The study revealed that the core business of the companies was sugar production with Mumias having diversified further into Ethanol, water and electricity generation. To effectively and efficiently meet their mandate, the companies have resulted in outsourcing noncore activities that include; security, legal services, cleaning, landscaping, land preparation, factory maintenance activities, sugar packaging, loading, and transportation. The outsourced services are in line with the findings of Owuor, 2016, study on the sugar millers in western Kenya. Only Mumias Sugar has outsourced cane transportation while the other companies considered it as core activity. From literature review, the motives to outsource include; cost reduction, corporate strategy, focus on core competencies, and access to specialized skills (Griffiths, 1999; Kakabadse \& Kakabadse, 2000; Isinga \& Werle, 2000). The findings of the study were in agreement with these motives. The level of skills and the amount of resource required to undertake an activity has greatly influenced the sourcing locality for various activities. 
The companies have documented their procurement process, which guides outsourcing of services. The process is classified into: initiation, identification, selection, and approval of vendors. These stages are in line with Perunovic \& Pedersen (2007) grouping of the stages in the outsourcing process frameworks. The study established that all vendors have signed contracts and that their supervision and performance evaluation is done by staff within their area of work.

The study revealed that outsourcing is beneficial to the companies. Some of the benefits listed were; increased focus on core competences, cost savings, access to specialized skills, freeing resources to other key areas, reduced staff numbers, converting fixed cost into variable cost, and improved quality of work. These findings were in agreement with literature review by Tuyauova (2012) and Manyasi \& Omusotsi (2014). Employees are involved in the outsourcing process by contributing towards the planning and during implementation by supervising and evaluating the performance of contractors.

The study established the challenges of outsourcing as ineffective management of the implementation process at initial stages, resistance to change from the workforce, and conflict of interest from employees. These findings were in line with those of Kiptoo, (2012); Ombasa, (2013); Sesi (2014). However the findings were contrary to Sesi (2014) who identified inadequate resource allocation as an outsourcing challenge by commercial banks in Kenya, and Ombasa (2013) who conducted a study on the implementation of outsourcing strategy at Kenya post office savings bank and found out that there was lack of support from the top leadership which affected the implementation process.

With regard to the measures put in place to deal with the challenges of outsourcing, the study established that the companies have ensured there is top management involvement as a group in all the outsourcing steps, corrective management action to resistance to change and having open channels of communication, and putting in place adequate policies and operating procedures to deal with the conflict of interest in line with the findings of Peng \& Littlejohn, 2001; DeLisi, 2001; and Kiptoo, 2012. It was also established that additional measures had been put in place to mitigate the challenges that included; prompt vendor payment, capacity building through targeted training program to the company employees and the contractors, redeployment of affected staff to other areas, retaining a small team after outsourcing the activity to coordinate the process, cascading budgeted resource utilization to all staff levels, and prioritizing local contractors and community when outsourcing non skilled activities.

Finally, the study was conducted as a multiple-case design and provided in-depth understanding of the implementation of outsourcing strategy in the three companies. This was unlike previous studies which conducted case study research (McIvor, 2003; Sesi, 2014; Kiptoo, 2012; Kipruto, 2014) while studying the implementation of outsourcing strategy in different industries. The study design sets the study apart from the more commonly used design in many outsourcing studies conducted by scholars.

\section{Conclusion}

The sugar industry in Kenya is currently facing a number of challenges that have greatly affected production, profitability, and general competitiveness of the industry. The companies have employed a number of strategies in response to the environmental challenges. The study concludes that outsourcing of noncore activities is one of the widely used beneficial strategies motivated by cost reduction, improvement of business focus on core competencies, access to specialized skills, and in the case of MSC reengineering benefits and freeing resources for other purposes.

It is concluded that MSC had the highest number of outsourced services while West Kenya had the least. This can be attributed to the number of years the companies have been in operation, ownership structure, and oversight system. The outsourcing process is documented within the procurement and finance policies of the company and it is mandatory to have a signed contract while providing services to the company. Regular operational and management meetings are used to manage the relationships between the two companies.

The study also concludes that the companies have experienced a number of challenges while implementing the outsourcing strategy like ineffective management of the implementation process, resistance to change, and conflict of interest from employees. The measures put in place to deal with these challenges include; involve top management in all the outsourcing steps; corrective management actions of; availing sufficient information about change, being empathetic to staff fears, and reducing employees frustrations through redeployments; having open communication channels within the organization, and putting in place adequate policies and operating procedures that guide members of staff while undertaking various activities. 
These findings are in tandem with empirical studies on the implementation of outsourcing strategy where challenges have been experienced but ultimately outsourcing success has been as a result of the mitigation measures set up to overcome these challenges.

Therefore, TCE and Agency theory provide a solid ground and can be applied in studies focusing on the implementation of outsourcing strategy.

\section{Recommendations for Policy and Practice}

Drawing from the implementation of outsourcing process, segregation of core and noncore activities has resulted in a number of differences. The stakeholders in the sugar industry should therefore compile a common list of core and noncore activities that should guide the outsourcing process within the industry with an aim of maximizing outsourcing benefits to the companies. Companies should also benchmark with the best in class to learn as well as share experiences and improve the measures already put in place.

The companies should also step up the enforcement of the current corporate rules, regulations, and policies that have been established to deal with conflict of interest and corrupt practices. The study established that the companies do not have a shortage of policies, but what could be lacking is the enforcement of these policies and failure to abide with the laid down procedure. Strict enforcement will go a long way in ensuring that cases of unqualified contractors being awarded contracts are eliminated, as well as reducing financial loss and loss of revenue to the company.

It is also recommended that dispute resolution mechanisms within the organization, on the part of the contractor, and between the two companies should be strengthened to be able to resolve cases as they occur. This will avoid interference with the operations of the company especially when the disputes are emanating from the outsourced service provider. The companies should also work on developing and improving contractor performance, monitoring and evaluation tools which were found to be non existence in some cases.

Regarding ineffective implementation of the outsourcing process, companies should come to the realization that implementation is only possible where the people involved have the right and relevant skills. This calls for renewed focus on the training program after establishing the skills gap that should establish the type, content, and the length of training required. Training should be undertaken at all levels involved in the implementation of the outsourcing strategy.

\section{Limitations of the Study}

In an effort to depict a superior image of the organization, the managers could have stated what is the ideal practice rather than what is currently ongoing. Only senior managers were interviewed for this study while actively engaged in their day to day management activities due to time constraints on their busy schedule.

Time constraints and financial limitations were experienced during the study. It was therefore not possible to visit all the companies in the sugar industry but the study settled on the three companies which are representative of the dominant ownership structure and are rich in information. Sony Sugar and Mumias sugar have also been experiencing cases of inadequate raw materials which has greatly reduced their operations in the current and last financial years.

Access to contracts signed with the service providers was limited due to the fact that they are still in place and the fact that they are held by the legal department. The managers were also reluctant to provide access to contractor evaluation reports, contracts, and minutes on renegotiation citing confidentiality. As such deficiencies in the contracts could not be established between the company and the vendor. However, the researcher was given access to previous contracts on the same activities.

The study was a multi-case study research, and due to the contextual nature of the three companies, the study findings on the implementation of outsourcing strategy at selected sugar companies cannot be generalized to the whole industry. This is because different companies adopt different strategies to have an edge over the competition.

\section{Suggestions for Further Study}

A replication of this study should be carried out after some time preferably after the privatization of the remaining state millers to find out if there are changes that have occurred and a comparison made with the current data. From this, the industry can gauge its readiness to compete with global competitors. 
In future, the research design can employ a qualitative methodology of data collection where data can be collected from all the companies in the sugar industry and a wider group of staff involved in the implementation of outsourcing process interviewed.

The study also recommends that further research should be carried out focusing on the challenges of implementing the outsourcing strategy in the sugar industry and the measures that the companies have set up against the challenges. This is because empirical studies on implementation challenges in other industries have not been applicable on the sugar industry. Further study should be done on the competitive strategies adopted by companies in the sugar industry since outsourcing is just but one of them that has been covered in this study.

\section{References}

Baker, S. L. (1987). Managing resistance to change. Allerton Park Institute (29th: 1987). Barthélemy, J. (2003). The seven deadly sins of outsourcing. Academy Of Management Executive, 17 (2), 87-98.

Blancero, D., \& Ellram, L. (1997). Strategic supplier partnering: A psychological contract perspective. International Journal of Physical Distribution \& Logistics Management, 27(9/10), 616-629.

Brown, D. \& Wilson, S. (2005). The Black Book of Outsourcing: How to manage the Changes, Challenges, and Opportunities, John Wiley \& Sons, Hoboken

Coase, R. (1973). The Nature of the Firm. Economica, N.S., 4(16): 386-405

David, F. (2007). Strategic Management: Cases and Concepts, Eaglewood Cliffs, NJ: Prentice-Hall.

DeLisi, P. (2001). Strategy Execution: An Oxymoron or a Powerful formula for Corporate success. rganizational Synergies. Retrieved from http://www.org- synergies.com.

Eisenhardt, K. (1989). Agency theory: An assessment and review. The Academy of Management Review, 14(1), $57-74$.

Gichohi, J. G. (2010). A Framework for Implementation of Business Process Outsourcing in Kenya. (Unpublished MBA Project). School of Business, University of Nairobi.,Kenya.

Griffiths, D. (2001). The Theory and Practice of Outsourcing. Kudos Information Ltd, England.

Higgins, J. M. (2005).The Eight 'S's of Successful Strategy Execution. Journal of Change Management, 5 (1), 313.

Isinga, R. C. and Werle M. J. (2000). Linking outsourcing to business strategy. Academy of Management Executive, 14 (4), 58-70.

Jensen, M., \& Meckling, W. (1976) Theory of the firm: Managerial behavior, agency costs, and ownership structure. Journal of Financial Economics, 3, 305-360.

Johnson, G., Scholes, K \& Whittington, R. (2008). 'Exploring corporate strategy-Text and cases' (8th Edition) Essex, England: Pearson Education.

Kakabadse, N. \&Kakabadse, A. (2000). Critical review-Outsourcing: a paradigm shift. Journal of Management Development, 19 (8),670-728

Kipkurui, A. K. (2015). Implementation of business process outsourcing by Government Agencies under the Ministry of information and communication technology in Kenya. (Unpublished MBA Project). School of Business, University of Nairobi., Kenya.

Kiptoo, K. (2012). Implementation Challenges of the Business Process Outsourcing Strategy in the Ministry of Transport in Kenya. (Unpublished MBA Project). School of Business, University of Nairobi., Kenya.

Michael Beer \& Rusell A. Eisenstat (2000). The silent killer of strategy implementation and learning. Sloan Management Review, 41, 29-40.

Mullin, R. (1996). Managing the Outsourced Enterprise. Journal of Business Strategy, 17 (4), 28-38.

Mumias Sugar Company Limited (n.d.) Mumias Sugar Company ltd website. Retrieved August 19, 2016, from http://www.mumias- $\quad$ sugar.com/index. php?page=Overview

Ochieng, P. (2009). Business process outsourcing implementation challenges in Kenya. Economic Review, 22 (94), 605-627.

Ombasa, J. M. (2013). Implementation of Outsourcing Strategy at Kenya Post Office Savings Bank. (Unpublished MBA Project). School of Business, University of Nairobi., Kenya.

Peng, W., and Littlejohn, D. (2001). Organizational Communication and strategy implementation-Aprimary inquiry. International Journal of Contemporary Hospitality, 13, 360-363. 
Perunovic, Z. and Pedersen, J. (2007). Outsourcing process and theories, Proceedings of the POMS 18th Annual conference, Dallas, Texas, U.S.A.

Porter, M. E. (1994). Competitive strategy revisited: A view from the 1990s. The relevance of a decade. Boston: Harvard Business School Press.

Quélin, B., \& Duhamel, F. (2003). Bringing together strategic outsourcing and corporate strategy: Outsourcing motives and risks. European management journal, 21(5), 647- 661.

Quinn, J. B. (1999). Strategic Outsourcing: Leveraging Knowledge Capabilities, Sloan Management Review, summer, pp. 43-55.

Quinn, J. B., \& Hilmer, F. G. (1994). Strategic outsourcing. Sloan management review, 35(4),43.

Ross, S. A. (1973). The economic theory of agency: The principal's problem. American Economic Review, 62(2) 134-139.

Sesi, C. O. (2014). Challenges of implementing outsourcing strategy by commercial Banks in Kenya. (Unpublished MBA Project). School of Business, University of Nairobi., Kenya.

Tayauova, G. (2012). Advantages and Disadvantages of Outsourcing: analysis of outsourcingpracticesof Kazakhstan banks. Procedia Social and Behavioral Sciences, 41, 188-195.Troacă, V. A., \& Bodislav, D. A. (2012). Outsourcing. The concept. Theoretical and Applied Economics, 6(6), 51.

Ulaga, W. \& Sharma, A. (2001). Complex and strategic decision making in organization: Implicationsfor personal selling and sales management. Industrial Marketing Management, 30(5), 427-440.

Vaxevanou, A., \& Konstantopoulos, N. (2015). Models referring to outsourcing theory. Procedia-Social and Behavioral Sciences, 175,572-578.

Williamson, O. E. (1979). Transaction-cost economics: The governance of contractual relations. The Journal of Law \& Economics, 22(2), 233-261.

Yin, R. K. (2003). Case Study Research: Design and methods, (3rd ed.). Thousand Oaks, CA: Sage Publications, Inc. 